\title{
Characteristics of social drinkers with and without a hangover after heavy alcohol consumption
}

\author{
A Hogewoning $1, *$ \\ AJAE Van de Loo',* \\ M Mackus' \\ SJ Raasveld' \\ R De Zeeuw' \\ ER Bosma' \\ NH Bouwmeester' \\ KA Brookhuis ${ }^{2}$ \\ J Garssen ${ }^{1,3}$ \\ JC Verster ${ }^{1,4}$
}

'Division of Pharmacology, Utrecht University, Utrecht, ${ }^{2}$ Faculty of Behavioral and Social Sciences, Groningen University, Groningen, ${ }^{3}$ Nutricia Research, Utrecht, the Netherlands; ${ }^{4}$ Centre for Human Psychopharmacology, Swinburne University, Melbourne, VIC, Australia

*These authors contributed equally to this work
This article was published in the following Dove Press journal:

Substance Abuse and Rehabilitation

17 November 2016

Number of times this article has been viewed

Background: A number of social drinkers claim that they do not experience next-day hangovers despite consuming large quantities of alcohol. The aim of this study was to investigate the characteristics of drinkers who claim to be hangover immune and compare them with drinkers who do report having hangovers.

Methods: A total of 36 social drinkers participated in a naturalistic study consisting of a hangover day (alcohol consumed) and a control day (no alcohol consumed). Data were collected on alcohol consumption, demographics, sleep, next-day adverse effects, and mood. Data from drinkers with a hangover $(\mathrm{N}=18)$ were compared with data from drinkers who claim to be hangover immune $(\mathrm{N}=18)$.

Results: Drinkers with a hangover reported drowsiness-related symptoms, symptoms related to reduced cognitive functioning, and classic hangover symptoms such as headache, nausea, dizziness, weakness, and stomach pain. Corresponding mood changes comprised increased feelings of depression, anger-hostility, fatigue, and reduced vigor-activity. In contrast, hangover-immune drinkers reported relatively few hangover symptoms, with only mild corresponding severity scores. The reported symptoms were limited to drowsiness-related symptoms such as sleepiness and being tired. The classic hangover symptoms were usually not reported by these drinkers.

Conclusion: In contrast to drinkers with a hangover, for those who claim to be hangover immune, next-day adverse effects of alcohol consumption are limited to a mild increase in drowsiness-related symptoms.

Keywords: alcohol, hangover, symptoms, mood, immunity

\section{Introduction}

The next-day negative effects of alcohol consumption are collectively called the alcohol hangover. ${ }^{1}$ The presence and severity of hangover symptoms, however, vary between drinking occasions and between drinkers. Penning et $\mathrm{al}^{2}$ summarized data from 1,410 Dutch students, reporting on the presence and severity of 49 potential hangover symptoms. A factor analysis revealed that the factor "drowsiness" (including symptoms such as fatigue, sleepiness, drowsiness, and weakness) and the factor "cognitive functioning" (including symptoms such as reduced alertness, memory, and concentration problems) were the most important factors describing the alcohol hangover. In addition to next-day negative hangover symptoms, mood may also be altered during the alcohol hangover. McKinney ${ }^{3}$ summarized data from seven studies that examined subjective mood states the day after heavy alcohol consumption. The analysis revealed that alcohol hangover is associated with increased anxiety and fatigue, decreased alertness and arousal, physical discomfort, and emotional disturbance.
Correspondence: JC Verster Division of Pharmacology, Utrecht Institute for Pharmaceutical Sciences, Utrecht University, Universiteitsweg 99, 3584CG Utrecht, the Netherlands

$\mathrm{Tel}+3$ I 302536909

Fax +3I 302537900

Email j.c.verster@uu.nl 
Alcohol hangover is the most commonly reported adverse effect of heavy alcohol consumption, and the majority of drinkers are familiar with this phenomenon. ${ }^{4}$ However, based on several experimental studies and survey data, Howland et $\mathrm{l}^{5}$ concluded that $20-25 \%$ of drinkers report no hangover symptoms after an evening of heavy drinking. Moreover, recent research showed that claiming hangover immunity heavily depends on the amount of alcohol consumed by drinkers. ${ }^{6}$ Data from 6,002 Dutch students revealed that the higher the estimated blood alcohol concentration (BAC), the less likely drinkers claimed to be hangover immune. For example, with a BAC above $0.20 \%$, only $8.1 \%$ of the drinkers reported not having a hangover. ${ }^{6}$ Despite this reduction in claims of hangover immunity at higher BACs, a small number of high-volume drinkers persist in reporting no nextday hangover effects.

Up until now, little is known about the small subset of drinkers who claim to be hangover immune. It is important, however, to further examine these hangover-immune drinkers and compare them with drinkers who do report next-day hangover effects. Comparing demographics, drinking behavior, and biomarkers of alcohol consumption of both groups may help to increase insight into the pathology of the alcohol hangover, which eventually may contribute to the development of an effective preventive measure or a hangover cure.

Therefore, the aim of this study was to compare the next-day effects of an evening of alcohol consumption on the presence and severity of hangover symptoms and mood of those regularly reporting a hangover with those claiming to be hangover immune. It was hypothesized that, in contrast to those drinkers who report having a hangover, those drinkers who claim to be hangover immune do not report significant mood changes or adverse effects the day after an evening of alcohol consumption.

\section{Methods}

\section{Design}

A naturalistic study approach was adopted to ensure mimicking of real-life drinking. The study composed of a hangover day (alcohol consumed the evening before) and a control day (no alcohol consumed the evening before). In contrast to experimental studies, in naturalistic studies, the researchers are not present during alcohol consumption and thus have no influence on the participants' behavior the evening before the test days, ie, participants decide themselves whether or not they consume alcohol and consume the beverages in a setting of their own choice (eg, at home or in a bar). Participants could choose their preferred types of beverages and quantity, as well as time to start and stop drinking. If participants chose not to consume alcohol, either the next day served as a control test day, or the hangover test day was postponed. Participants slept at home and were asked to be present at the institute at 09.00 am next morning. Although a naturalistic study design was applied, there were a few restrictions to be included in the final data set. For a control day to be valid, participants were not allowed to consume alcohol at least 24 hours prior to the test day. They were also not allowed to use recreational drugs, and on both test days the consumption of caffeinated beverages was not allowed. Written informed consent was obtained from each participant, and the study protocol was approved by the University of Groningen Psychology Ethics Committee. Subjects received 80 Euro for participating in the study, and their travel expenses were reimbursed.

\section{Participants}

Participants were recruited by local advertisement. The aim was to include two groups of participants: 1) 18 participants who reported having hangovers after an evening of alcohol consumption, and 2) 18 participants who reported to be hangover immune. The sample size of 18 per group was based on a previous research. ${ }^{2}$ Assuming $85 \%$ of power and a two-sided significance level of 0.05 , a sample size of 18 subjects per group would be able to detect a difference in hangover severity scores between the hangover group and the hangover-immune group of two (eg, hangover group score: 2.5; hangover-immune group score: 0.5 ), assuming a within-subject SD of 1.5 .

As it was essential that both groups consumed sufficient alcohol to produce a hangover per se, participants were selected based on their usual alcohol consumption pattern within a certain time period. Taking into account gender and body weight, their estimated peak BAC for such drinking occasions was computed according to the formula by Matthews and Miller. ${ }^{7}$ If the estimated peak BAC was higher than $0.08 \%$, participants were considered eligible to participate in the study. Participants were included if they were healthy social drinkers, not using recreational drugs (other than alcohol), nonsmoking, and were $18-30$ years old. Participants were excluded from further participation if a positive urine drug or pregnancy screen was obtained, and in case of using medicinal drugs (including over-the-counter pain killers), caffeine consumption on test days, or alcohol consumption within 24 hours before the start of the control test day. 


\section{Assessments during screening}

During screening, demographic data from the participants as well as information on current alcohol consumption patterns were obtained. In addition, the Alcohol Use Disorders Identification Test (AUDIT) and Self-Rating of the Effects of alcohol (SRE) form were completed. The AUDIT is a 10-item questionnaire used to identify drinkers with a hazardous and harmful pattern of alcohol consumption. ${ }^{8}$ The SRE is a retrospective measure assessing the level of response to alcohol and contains 12 questions on the number of drinks needed to experience possible effects of alcohol consumption. ${ }^{9}$ The effects are, 1) to "begin to feel any different" (any effect); 2) "to feel a bit dizzy or begin to slur your speech"; 3) "to begin stumbling or walking in an uncoordinated manner"; and 4) to "pass out, or fall asleep when you did not want to". These were rated by the person during the following three time frames: the first five times (first 5) they had ever taken a drink (early life), the most recent three consecutive months on which drinking occurred, and during their period of heaviest drinking. The SRE total score and SRE early life score were computed. A lower score on the SRE implies that more alcoholic drinks are needed to achieve a certain effect (eg, passing out).

\section{Assessments on test days}

All assessments were conducted in the morning, starting at $09.30 \mathrm{am}$.

\section{Drug screening}

A urine drug screen (Instant-View, determining the presence of amphetamines, barbiturates, cannabinoids, benzodiazepines, cocaine, and opiates) was conducted according to the manufacturer's instructions (Alfa Scientific Designs, Inc, Poway, CA, USA). None of the participants tested positive for drug use on the test days.

\section{Sleep}

After arrival at the institute, at each test day, participants completed the Karolinska Sleepiness Scale (KSS) and the Groningen Sleep Quality Scale (GSQS). The KSS was completed to rate the participants' level of subjective sleepiness. Participants had to choose one of nine statements about their current state of sleepiness ranging from 1 (extremely alert) to 9 (extremely sleepy, fighting sleep).${ }^{10}$ In the GSQS, participants had to answer whether they agree or disagree with propositions about their sleep quality the previous night. ${ }^{11}$ The GSQS contains 14 items on sleep quality. The overall GSQS score ranges from 0 to 14 , with the higher the score the lower the subjective quality of sleep. In addition, participants were asked to answer seven questions regarding the duration of their sleep, time to fall asleep and wake up, and number of nightly awakenings.

\section{Drinking behavior and activities on the evening before test days}

Participants listed the number and type of alcoholic beverages that were consumed the evening before the test day. Standard drinking sizes were mentioned on the form. Start and stop time of alcohol consumption were recorded to calculate an estimated peak BAC.

\section{Hangover symptoms}

Overall hangover severity (ie, a single one-item rating) and the severity of 23 individual symptoms were rated on an 11-point scale ranging from 0 (absent) to 10 (extreme). The 23 items were derived from the Alcohol Hangover Severity Scale, the Hangover Symptoms Scale, and the Acute Hangover Scale. ${ }^{12-14}$ The rationale for assessing individual hangover symptoms instead of using one of the three scales is the fact that they each list different hangover symptoms. For example, the Alcohol Hangover Severity Scale does not assess headache, which is, however, a commonly reported hangover symptom. Another example is weakness, which is assessed by the Hangover Symptom Scale, but not by the two other scales. By using the composite 23 -item scale, all symptoms from the three hangover scales are assessed, providing a more complete overview of the hangover state.

\section{Mood}

Mood was assessed using a short version of the Profiles of Mood States (POMS). ${ }^{15}$ The Dutch short version of the POMS contains 32 items that can be scored on a 5-point Likert scale, ranging from 0 (not at all) to 4 (extremely). ${ }^{16}$ The items can be combined into five subscales, including 1) tension-anxiety, 2) depression, 3) anger-hostility, 4) vigoractivity, and 5) fatigue.

\section{Statistical analyses}

Statistical analyses were performed using SPSS (Version 23). To compare the hangover group and hangoverimmune group, the collected data were compared using an independent-samples $t$-test, or nonparametric statistics (independent-samples Mann-Whitney $U$ test). For correlational analyses, delta scores (hangover-control day) were computed for each variable. Delta scores were correlated (nonparametric, Spearman's $\rho$ ) with the overall one-item hangover severity score. 


\section{Results}

A total of 36 participants completed the study. Of them, 18 (ten women and eight men) reported being hangover immune and 18 (12 women and six men) reported a hangover. The hangover-immune and hangover groups did not differ significantly on age, height, weight, and body mass index (Table 1). As assessed with the SRE, the groups also did not differ in sensitivity to the effects of alcohol. Participants of the hangover group did score significantly higher on some of the AUDIT items, and the corresponding overall AUDIT score (Table 2).

On the evening of alcohol consumption, no significant differences were observed between the hangover group and the hangover-immune group on the number of alcoholic drinks consumed (11.6 drinks on average), estimated peak BAC ( $\sim 0.175 \%)$, and total drink time (Table 3$)$.

Relative to the control day, after alcohol consumption, participants of both groups reported significantly shorter total sleep time and poorer sleep quality (Table 4). No significant differences were observed between the groups on the control day. Sleepiness scores, as assessed with the KSS, were significantly higher on the alcohol day compared with the control day. However, the day after alcohol consumption, participants of the hangover group reported significantly higher sleepiness scores compared with participants of the hangover-immune group.

Overall hangover severity, the day after alcohol consumption, as assessed by a one-item score, was significantly higher in the hangover group (5.9) compared with the hangoverimmune group (0.3). On both the hangover and control day, the severity of 23 individual hangover symptoms was also scored (Table 5). On the control day, most hangover symptom scores were close to zero, and no relevant differences were observed between the hangover group and the hangoverimmune group.

The hangover group endorsed most hangover symptoms on the day after alcohol consumption, and except for anxiety and depression, scores on the hangover day were significantly

Table I Demographics

\begin{tabular}{|c|c|c|c|}
\hline & \multirow{2}{*}{$\begin{array}{l}\text { Hangover-immune } \\
\text { group }(\mathrm{N}=18 ; \\
10 \text { women } / 8 \text { men) } \\
\text { Mean }(\mathrm{SD})\end{array}$} & \multicolumn{2}{|c|}{$\begin{array}{l}\text { Hangover } \\
\text { group }(\mathrm{N}=18 ; \\
\text { I } 2 \text { women/6 men) }\end{array}$} \\
\hline & & Mean (SD) & $p$-value \\
\hline Age (years) & $20.8(2.0)$ & $21.4(1.6)$ & 0.314 \\
\hline Height (m) & I.78 (0.I) & $\mathrm{I} .76(0.1)$ & 0.470 \\
\hline Weight (kg) & 7I.I (I0.2) & $67.2(11.5)$ & 0.289 \\
\hline BMI $\left(\mathrm{kg} / \mathrm{m}^{2}\right)$ & $22.3(2.0)$ & $21.7(2.6)$ & 0.404 \\
\hline
\end{tabular}

Abbreviation: BMI, body mass index.
Table 2 Alcohol consumption patterns

\begin{tabular}{|c|c|c|}
\hline & $\begin{array}{l}\text { Hangover-immune } \\
\text { group } \\
\text { Mean (SD) }\end{array}$ & $\begin{array}{l}\text { Hangover } \\
\text { group } \\
\text { Mean (SD) }\end{array}$ \\
\hline SRE total score & $8.5(4.8)$ & $8.2(4.2)$ \\
\hline SRE early life & $4.3(1.5)$ & $4.4(1.9)$ \\
\hline AUDIT total score & II.I (4.3) & $14.6(4.0)^{*}$ \\
\hline $\begin{array}{l}\text { AUDIT-I (How often do you } \\
\text { have a drink containing alcohol?) }\end{array}$ & $2.9(0.5)$ & $2.9(0.6)$ \\
\hline $\begin{array}{l}\text { AUDIT-2 (How many units of } \\
\text { alcohol do you drink on a typical } \\
\text { day when you are drinking?) }\end{array}$ & $1.9(1.2)$ & $2.2(1.2)$ \\
\hline $\begin{array}{l}\text { AUDIT-3 (How often have you } \\
\text { had six or more units if female, } \\
\text { or eight or more if male, on a } \\
\text { single occasion in the last year?) }\end{array}$ & $2.6(0.6)$ & $2.6(0.6)$ \\
\hline $\begin{array}{l}\text { AUDIT-4 (How often during the } \\
\text { last year have you found that } \\
\text { you were not able to stop } \\
\text { drinking once you had started?) }\end{array}$ & $0.8(098)$ & I. $4(0.8)^{*}$ \\
\hline $\begin{array}{l}\text { AUDIT-5 (How often during the } \\
\text { last year have you failed to do } \\
\text { what was normally expected } \\
\text { from you because of drinking?) }\end{array}$ & $0.4(0.6)$ & I.I $(0.9)^{*}$ \\
\hline $\begin{array}{l}\text { AUDIT-6 (How often during } \\
\text { the last year have you needed } \\
\text { an alcoholic drink in the } \\
\text { morning to get yourself going } \\
\text { after a heavy drinking session?) }\end{array}$ & $0.1(0.2)$ & $0.3(0.6)$ \\
\hline $\begin{array}{l}\text { AUDIT-7 (How often during the } \\
\text { last year have you had a feeling of } \\
\text { guilt or remorse after drinking?) }\end{array}$ & $0.9(0.8)$ & $1.4(0.8)$ \\
\hline $\begin{array}{l}\text { AUDIT-8 (How often during the } \\
\text { last year have you been unable } \\
\text { to remember what happened } \\
\text { the night before because you } \\
\text { had been drinking?) }\end{array}$ & $0.6(0.6)$ & I.3 $(0.6)^{*}$ \\
\hline $\begin{array}{l}\text { AUDIT-9 (Have you or someone } \\
\text { else been injured as a result of } \\
\text { your drinking?) }\end{array}$ & $0.4(1.1)$ & $0.8(1.4)$ \\
\hline $\begin{array}{l}\text { AUDIT-I0 (Has a relative or } \\
\text { friend or a doctor or another } \\
\text { health worker been concerned } \\
\text { about your drinking or suggested } \\
\text { you cut down?) }\end{array}$ & $0.4(1.3)$ & $0.6(I . I)$ \\
\hline
\end{tabular}

Note: Significant differences $(p<0.05)$ are indicated by $*$.

Abbreviations: AUDIT, Alcohol Use Disorders Identification Test; SRE, SelfRating of the Effects of alcohol.

higher compared with the control day. The highest severity scores were obtained for drowsiness-related symptoms such as sleepiness (6.1), being tired (6.1), and concentration problems (5.3). However, participants of the hangover group also scored significantly higher on symptoms that are more likely to limit performing daily activities such as headache (5.3), nausea (4.8), weakness (4.6), dizziness (3.6), and stomach pain (3.3). 
Table 3 Alcohol consumption on the test day

\begin{tabular}{|c|c|c|c|}
\hline & \multirow{2}{*}{$\begin{array}{l}\text { Hangover- } \\
\text { immune group } \\
\text { Mean (SD) }\end{array}$} & \multicolumn{2}{|l|}{ Hangover group } \\
\hline & & Mean (SD) & $p$-value \\
\hline $\begin{array}{l}\text { Number of alcoholic } \\
\text { drinks }\end{array}$ & $10.7(4.7)$ & $12.5(7.3)$ & 0.563 \\
\hline Start time drinking $(\mathrm{h}: \mathrm{m})$ & $21: 06(1 \mathrm{~h}, 44 \mathrm{~m})$ & $20: 06(1 \mathrm{~h}, 52 \mathrm{~m})$ & $0.000 *$ \\
\hline Stop time drinking (h:m) & 0I:52 (I h, $37 \mathrm{~m})$ & $02: 18(1 \mathrm{~h}, 44 \mathrm{~m})$ & $0.006 *$ \\
\hline Total drink time $(\mathrm{h})$ & $4.9(2.0)$ & $6.2(1.8)$ & 0.059 \\
\hline Estimated BAC (\%) & $0.165(0.07)$ & $0.187(0.09)$ & 0.265 \\
\hline
\end{tabular}

Note: Significant differences $(p<0.05)$ are indicated by $*$

Abbreviations: BAC, blood alcohol concentration; h, hour; $m$, minutes.

Table 4 Sleep

\begin{tabular}{|c|c|c|c|c|}
\hline & \multicolumn{2}{|c|}{$\begin{array}{l}\text { Hangover-immune } \\
\text { group }\end{array}$} & \multicolumn{2}{|c|}{ Hangover group } \\
\hline & Control & Hangover & Control & Hangover \\
\hline $\begin{array}{l}\text { Reduced sleep } \\
\text { quality (GSQS) }\end{array}$ & $2.9(3.4)$ & $4.7(1.9)^{\mathrm{a}}$ & $3.2(3.4)$ & $5.2(1.9)$ \\
\hline Time to bed (h:m) & $\begin{array}{l}00: 45 \\
(1 \mathrm{~h}, 43 \mathrm{~m})\end{array}$ & $\begin{array}{l}02: 49 \\
(1 \mathrm{~h}, 37 \mathrm{~m})^{\mathrm{a}}\end{array}$ & $\begin{array}{l}00: 49 \\
(1 \mathrm{~h}, 12 \mathrm{~m})\end{array}$ & $\begin{array}{l}03: 18 \\
(1 \mathrm{~h}, 36 \mathrm{~m})^{\mathrm{a}, \mathrm{b}}\end{array}$ \\
\hline $\begin{array}{l}\text { Total sleep time } \\
(\mathrm{h}, \mathrm{m})\end{array}$ & $7 \mathrm{~h}, 29 \mathrm{~m}$ & $5 \mathrm{~h}, 58 \mathrm{~m}^{\mathrm{a}}$ & $7 \mathrm{~h}, 26 \mathrm{~m}$ & $5 \mathrm{~h}, 36 \mathrm{~m}^{\mathrm{a}}$ \\
\hline Nightly awakenings & $0(0.50)$ & $1.2(1.09)$ & I (I.I7) & $I(I .12)$ \\
\hline Sleepiness (KSS) & $3.9(1.8)$ & $5.6(1.7)^{\mathrm{b}}$ & $4.1(1.6)$ & $7.2(I .2)^{\mathrm{a}, \mathrm{b}}$ \\
\hline
\end{tabular}

Notes: Mean (SD) is shown. a Significant difference $(p<0.05)$ between hangover and control day (within groups). 'bignificant difference $(p<0.05)$ between hangoverimmune group and hangover group.

Abbreviations: GSQS, Groningen Sleep Quality Scale; KSS, Karolinska Sleepiness Scale; h, hour; m, minutes.

In contrast, the hangover-immune group endorsed only a few hangover symptoms, and the scores were generally low (a maximum of 2.5 out of 10). Endorsed symptoms that were significantly elevated in this group relative to the control day comprised sleepiness, being tired, concentration problems, thirst, and clumsiness. No significantly increased scores were observed on any of the more disabling symptoms such as headache and nausea. For all symptoms, except anxiety and depression, symptom severity scores were significantly lower in the hangover-immune group than those reported by the hangover group.

The effects of alcohol consumption on mood were significantly more pronounced in the hangover group compared with the hangover-immune group (Table 6). Regarding mood, the day after alcohol consumption, the hangover group scored significantly higher on the subscales of depression, anger-hostility, and fatigue and significantly lower on vigor-activity. In contrast, the hangover-immune group only scored significantly higher on the fatigue scale and significantly lower on the vigor-activity scale. For both groups, no significant effects were seen on the tension-anxiety scale.
Table 5 Hangover symptom severity

\begin{tabular}{|c|c|c|c|c|}
\hline & \multirow{2}{*}{\multicolumn{2}{|c|}{$\begin{array}{l}\text { Hangover-immune } \\
\text { group } \\
\text { Mean (SD) }\end{array}$}} & \multicolumn{2}{|c|}{ Hangover group } \\
\hline & & & Mean (SL & \\
\hline & Control & Hangover & Control & Hangover \\
\hline $\begin{array}{l}\text { I-item hangover } \\
\text { score }\end{array}$ & $0.0(0.0)$ & $0.3(0.5)^{\mathrm{a}}$ & $0.0(0.0)$ & $5.9(2.0)^{a, b}$ \\
\hline Sleepiness & $1.2(1.6)$ & $2.1(1.6)^{\mathrm{a}}$ & $1.9(2.0)$ & $6.1(2.3)^{\mathrm{a}, \mathrm{b}}$ \\
\hline Tiredness & $\mathrm{I} .2(\mathrm{I} .5)$ & $2.5(1.6)^{\mathrm{a}}$ & I.8 (2.0) & $6.1(2.7)^{\mathrm{a}, \mathrm{b}}$ \\
\hline Thirst & I.I (I.3) & $2.5(2.0)^{\mathrm{a}}$ & $\mathrm{I} .7(\mathrm{I} .4)$ & $5.9(2.5)^{\mathrm{a}, \mathrm{b}}$ \\
\hline Headache & $0.2(0.7)$ & $0.3(0.8)$ & $0.8(I . I)^{a}$ & $5.3(2.9)^{a, b}$ \\
\hline $\begin{array}{l}\text { Concentration } \\
\text { problems }\end{array}$ & $0.3(0.6)$ & I.I $(1.3)^{\mathrm{a}}$ & $0.9(1.1)$ & $5.1(2.1)^{\mathrm{a}, \mathrm{b}}$ \\
\hline Nausea & $0.0(0.0)$ & $0.1(0.3)$ & $0.1(0.3)$ & $4.8(3.1)^{\mathrm{a}, \mathrm{b}}$ \\
\hline Weakness & $0.2(0.7)$ & $0.6(I . I)$ & $0.5(0.6)$ & $4.6(2.7)^{\mathrm{a}, \mathrm{b}}$ \\
\hline Dizziness & $0.0(0.0)$ & $0.2(0.7)$ & $0.2(0.5)$ & $3.6(2.9)^{\mathrm{a}, \mathrm{b}}$ \\
\hline Clumsiness & $0.1(0.2)$ & $0.7(1.0)^{\mathrm{a}}$ & $0.2(0.4)$ & $3.4(2.7)^{\mathrm{a}, \mathrm{b}}$ \\
\hline Stomach pain & $0.0(0.0)$ & $0.0(0.0)$ & $0.5(1.3)$ & $3.3(3 . I)^{\mathrm{a}, \mathrm{b}}$ \\
\hline Apathy & $0.0(0.0)$ & $0.6(1.3)$ & $0.2(0.4)$ & $3.0(2.7)^{\mathrm{a}, \mathrm{b}}$ \\
\hline Shaking, shivering & $0.0(0.0)$ & $0.2(0.7)$ & $0.1(0.3)$ & $2.5(2.8)^{\mathrm{a}, \mathrm{b}}$ \\
\hline Regret & $0.1(0.2)$ & $0.1(0.2)$ & $0.1(0.2)$ & $2.4(2.9)^{\mathrm{a}, \mathrm{b}}$ \\
\hline Reduced appetite & $0.0(0.0)$ & $0.2(0.6)$ & $0.1(0.2)$ & $2.4(3.0)^{\mathrm{a}, \mathrm{b}}$ \\
\hline Heart beating & $0.0(0.0)$ & $0.0(0.0)$ & $0.1(0.2)$ & $2.1(2.4)^{a, b}$ \\
\hline Vomiting & $0.1(0.2)$ & $0.0(0.0)$ & $0.0(0.0)$ & $2.0(2.9)^{a, b}$ \\
\hline Confusion & $0.1(0.2)$ & $0.1(0.3)$ & $0.1(0.3)$ & $1.8(2.4)^{\mathrm{a}, \mathrm{b}}$ \\
\hline Sensitivity to light & $0.1(0.5)$ & $0.4(1.4)$ & $0.1(0.3)$ & $1.7(2.0)^{\mathrm{a}, \mathrm{b}}$ \\
\hline Sleep problems & $0.1(0.3)$ & $0.3(1.0)$ & $0.5(1.5)$ & $1.6(2.1)^{\mathrm{b}}$ \\
\hline Heart racing & $0.1(0.2)$ & $0.0(0.0)$ & $0.0(0.0)$ & $\mathrm{I} .4(2.3)^{\mathrm{a}, \mathrm{b}}$ \\
\hline Sweating & $0.1(0.2)$ & $0.1(0.5)$ & $0.3(0.7)$ & $\mathrm{I} .2(\mathrm{I} .8)^{\mathrm{a}, \mathrm{b}}$ \\
\hline Anxiety & $0.1(0.5)$ & $0.0(0.0)$ & $0.1(0.3)$ & $0.6(1.2)$ \\
\hline Depression & $0.2(0.5)$ & $0.1(0.2)$ & $0.1(0.2)$ & $0.4(1.0)$ \\
\hline
\end{tabular}

Notes: aSignificant difference $(p<0.05)$ between hangover and control day (within groups). 'bSignificant difference $(p<0.05)$ between hangover-immune group and hangover group.

\section{Table 6 Mood}

\begin{tabular}{|c|c|c|c|c|}
\hline & \multicolumn{2}{|c|}{$\begin{array}{l}\text { Hangover-immune } \\
\text { group }\end{array}$} & \multicolumn{2}{|c|}{ Hangover group } \\
\hline & Control & Hangover & Control & Hangover \\
\hline Depression & $0.6(1.7)$ & $0.3(0.8)$ & $0.6(1.2)$ & $1.7(2.6)^{a, b}$ \\
\hline Anger-hostility & $0.6(1.7)$ & $0.7(1.1)$ & I.3 (2.6) & $3.3(3.7)^{\mathrm{a}, \mathrm{b}}$ \\
\hline Vigor-activity & $10.4(3.3)$ & $7.1(3.2)^{b}$ & $9.6(4.2)$ & $3.5(3.3)^{\mathrm{a}, \mathrm{b}}$ \\
\hline Fatigue & $2.0(2.8)$ & $4.8(5.3)^{b}$ & $2.9(2.8)$ & $9.9(5.6)^{\mathrm{a}, \mathrm{b}}$ \\
\hline Tension-anxiety & $1.2(2.2)$ & $0.7(1.3)$ & $0.9(1.7)$ & $2.2(3.3)$ \\
\hline
\end{tabular}

Notes: Mean (SD) is shown. aSignificant difference $(p<0.05)$ between hangoverimmune group and hangover group. bSignificant difference $(p<0.05)$ between hangover and control day (within groups).

\section{Correlates of the alcohol hangover}

To determine potential factors that may influence the presence and severity of alcohol hangover, several factors related to alcohol consumption and sleep parameters were correlated with overall hangover severity, as assessed with the oneitem overall hangover score (these analyses were conducted only for participants belonging to the hangover group). The analyses revealed no significant association between 
hangover severity and the number of alcoholic drinks consumed ( $r=-0.113, p=0.656$ ), nor with estimated peak BAC ( $r=0.147, p=0.560)$. Hangover severity was also not related to any of the demographic variables, including those related to alcohol consumption patterns such as scores on the SRE and AUDIT or sleep-related parameters.

The amount of alcohol consumed was significantly associated with reported sleepiness on the KSS ( $r=0.533$, $p=0.023$ ), whereas the estimated peak BAC was significantly correlated with scores on the mood scales such as vigoractivity $(r=-0.520, p=0.027)$ and fatigue $(r=0.545, p=0.019)$ and reported sleepiness on the KSS $(r=0.601, p=0.008)$.

\section{Discussion}

The results of this study confirm that drinkers who claim to be hangover immune do exist and they provide a first thorough insight into how these drinkers differ from those who do report a hangover. Despite drinking large quantities of alcohol, these drinkers report relatively few hangover symptoms, with only mild corresponding severity scores. Of importance, the hangover items these hangover-immune drinkers endorse are limited to drowsiness-related symptoms such as sleepiness and being tired. In addition, the reported mood changes among these drinkers are limited to reduced vigor-activity scores and increased fatigue scores. The classic hangover symptoms such as headache, nausea, dizziness, weakness, and stomach pain are usually not reported by these drinkers. As these symptoms are likely to have a negative impact on the performance of daily activities such as driving a car or job performance, it is understandable that drinkers whose negative after-effects are limited only to mild drowsiness-related effects do not consider themselves to have an alcohol hangover. The latter is illustrated by the overall one-item hangover severity score of the hangover group which is close to zero, despite mild scores on drowsinessrelated hangover symptoms.

In contrast, the participants of the hangover group did report all classic hangover symptoms known from the literature. ${ }^{2}$ Besides drowsiness-related symptoms and symptoms related to reduced cognitive functioning, the majority of these drinkers also scored relatively high on more disabling symptoms such as headache, nausea, and stomach pain. Corresponding to these hangover symptoms are mood changes, illustrated by significantly increased scores on POMS scales of depression and anger-hostility, in addition to the reduced vigor-activity and increased fatigue scores which were also seen in the hangover-immune group. The observed effects in the hangover group were in line with those reported in the previous research assessing hangover-related mood changes. ${ }^{17-23}$ Overall hangover severity showed not to be significantly related to total alcohol consumption or estimated peak BAC.

The findings among those who do report a hangover are in line with the previous research. Unfortunately, there is no previous research on the characteristics of drinkers who claim to be hangover immune. Therefore, a replication of this study and future research characterizing hangover-immune drinkers is warranted.

The importance of the current findings lies in the fact that the existence of hangover-immune drinkers may provide leads to elucidate the pathology of the alcohol hangover. Currently, although the pathology of hangover is poorly understood $^{24}$ and no effective treatments are available, ${ }^{25}$ several biobehavioral correlates of the alcohol hangover state have been reported (eg, changes in cytokine profiles), which may differ between hangover and hangover-immune drinkers. Alternatively, differences may be present in the way alcohol is metabolized by the two groups (eg, slow versus fast metabolizers). A limitation of the current study is that measurements were conducted solely at a single time point of the hangover day. McKinney and Coyle ${ }^{22}$ have shown that the presence and severity of hangover symptoms may vary during the day. Future research should therefore replicate these findings and examine participants at multiple time points during the day. From the data collected in this study, no obvious differences were found in demographics or alcohol consumption patterns that can explain why some drinkers experience a hangover and other do not. Future research should therefore explore other possible differences between these groups, such as alcohol metabolism or immune responses caused by alcohol intoxication. If differences between the two groups can be found on related biomarkers, such as cytokine concentrations or ethanol metabolites in urine, saliva, or blood, these may help to further elucidate the pathology of the alcohol hangover and explain why some drinkers claim to be hangover immune.

\section{Conclusion}

The next-day effects of alcohol consumption in drinkers who claim to be hangover immune are limited to mild effects on drowsiness and alertness. To this extent, these drinkers differ significantly from those who do report hangovers. These drinkers report similar drowsiness-related next-day effects, but the magnitude of these effects is much larger. In addition, they report the classic hangover symptoms such as headache, nausea and weakness, which are not reported by drinkers who claim to be hangover immune. 


\section{Acknowledgment}

This work was supported by Utrecht University.

\section{Disclosure}

JCV has received grants/research support from the Dutch Ministry of Infrastructure and the Environment, Janssen Research and Development, Nutricia Research, Takeda, and Red Bull and has acted as a consultant for the Canadian Beverage Association, Centraal Bureau Drogisterijbedrijven, Coleman Frost, Danone, Deenox, Eisai, J\&J, Jazz, Purdue, Red Bull, Sanofi-Aventis, Sen-Jam Pharmaceutical, Sepracor, Takeda, Transcept, Trimbos Institute, and Vital Beverages. KAB has received grants/research support from NWO, the Dutch Ministry of Infrastructure and the Environment, European Commission, Wyeth, Sanofi, Schering, Nissan, JARI, Mercedes Benz, and Verbond van Verzekeraars. JG is part-time employee of Nutricia Research. The other authors report no conflicts of interest in this work.

\section{References}

1. Prat G, Adan A, Sanchez-Tuert M. Alcohol hangover: a critical review of explanatory factors. Hum Psychopharmacol Clin Exp. 2009;24(4):259-267.

2. Penning R, McKinney A, Verster JC. Alcohol hangover symptoms and their contribution to the overall hangover severity. Alcohol Alcohol. 2012;47(3):248-252.

3. McKinney A. A review of the next day effects of alcohol on subjective mood ratings. Curr Drug Abuse Rev. 2010;3(2):88-91.

4. Verster JC, Stephens R, Penning R, et al; Alcohol Hangover Research Group. The Alcohol Hangover Research Group consensus statement on best practice in alcohol hangover research. Curr Drug Abuse Rev. 2010;3(2):116-127.

5. Howland J, Rohsenow DJ, Edwards EM. Are some drinkers resistant to hangover: a literature review. Curr Drug Abuse Rev. 2008;1:42-46.

6. Verster JC, de Klerk S, Bervoets AC, Kruisselbrink LD. Can hangover immunity be really claimed? Curr Drug Abuse Rev. 2013;6:253-254.

7. Matthews DB, Miller WR. Estimating blood alcohol concentration: two computer programs and their applications in therapy and research. Addict Behav. 1979;4:55-60.

8. Bohn MJ, Babor TF, Kranzler HR. The Alcohol Use Disorders Identification Test (AUDIT): validation of a screening instrument for use in medical settings. J Stud Alcohol. 1995;56(4):423-432.
9. Schuckit MA, Smith TL, Tipp JE. The self-rating of the effects of alcohol (SRE) form a retrospective measure of the risk for alcoholism. Addiction. 1997;92:979-988.

10. Åkerstedt T, Gillberg M. Subjective and objective sleepiness in the active individual. Int $J$ Neurosci. 1990;52:29-37.

11. Mulder-Hajonides van der Meulen WREH, Wijnberg JR, Hollander JJ, De Diana IPF, Van den Hoofdakker RH. Measurement of subjective sleep quality. Eur Sleep Res Soc. 1980;5:98.

12. Penning R, McKinney A, Bus LD, Olivier B, Slot K, Verster JC. Measurement of alcohol hangover severity: development of the alcohol hangover severity scale (AHSS). Psychopharmacology. 2013;225(4): 803-810.

13. Slutske WS, Piasecki TM, Hunt-Carter EE. Development and initial validation of the Hangover Symptoms Scale: prevalence and correlates of hangover symptoms in college students. Alcohol Clin Exp Res. 2003;27(9):1442-1450.

14. Rohsenow DJ, Howland J, Minsky SJ, Greece J, Almeida A, Roehrs TA. The acute hangover scale: a new measure of immediate hangover symptoms. Addict Behav. 2007;32(6):1314-1320.

15. McNair DM, Lorr M, Droppleman L. Manual for the Profile of Mood States. San Diego, CA: Educational and Industrial Testing Service; 1971.

16. Van der Ark LA, Marburger D, Mellenbergh GJ, Vorst HC, Wald FD. Verkorte Profile of Mood States (Verkorte POMS); Handleiding en verantwoording. Lisse: Swets Testing Services; 2003.

17. Myrsten AL, Rydberg U, Idstrom CM, Lamble R. Alcohol intoxication and hangover: modification of hangover by chlormethiazole. Psychopharmacology. 1980;69(2):117-125.

18. Collins WE, Chiles WD. Laboratory performance during acute alcohol intoxication and hangover. Hum Factors. 1980;22:445-462.

19. Chait LD, Perry JL. Acute and residual effects of marijuana, alone and in combination, on mood and performance. Psychopharmacology. 1994;115:340-349.

20. Finnigan F, Hammersley RH, Cooper T. An examination of next-day hangover effects after a $100 \mathrm{mg} / 100 \mathrm{ml}$ dose of alcohol in heavy social drinkers. Addiction. 1998;12(12):1829-1838.

21. Finnigan F, Schulze D, Smallwood J, Helander H. The effects of selfadministered alcohol-induced 'hangover' in a naturalistic setting on psychomotor and cognitive performance and subjective state. Addiction. 2005;100:1680-1689.

22. McKinney A, Coyle K. Alcohol hangover effects on measures of affect the morning after a normal night's drinking. Alcohol Alcohol. 2006;41(1):54-60.

23. Howland J, Rohsenow DJ, Greece JA, et al. The effects of binge drinking on college student's next-day academic test-taking performance and mood state. Addiction. 2010;105:655-665.

24. Penning R, van Nuland M, Fliervoet LAL, Olivier B, Verster JC. The pathology of alcohol hangover. Curr Drug Abuse Rev. 2010;3(2):68-75.

25. Pittler MH, Verster JC, Ernst E. Interventions for preventing or treating alcohol hangover: systematic review of randomized trials. $\mathrm{Br} \mathrm{Med} J$. 2005;331:1515-1518.
Substance Abuse and Rehabilitation

\section{Publish your work in this journal}

Substance Abuse and Rehabilitation is an international, peer-reviewed, open access journal publishing original research, case reports, editorials, reviews and commentaries on all areas of addiction and substance abuse and options for treatment and rehabilitation. The manuscript management system is completely online and includes a very quick and fair

\section{Dovepress}

peer-review system. Visit http://www.dovepress.com/testimonials.php to read real quotes from published authors. 